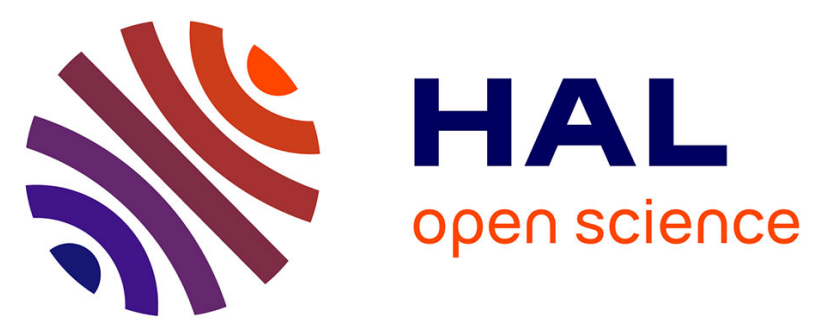

\title{
Thermal-ablation of vertebral metastases prevents adverse events in patients with differentiated thyroid carcinoma
}

\author{
M. Barat, L. Tselikas, T. de Baère, G. Gravel, S. Yevich, A. Delpla, N. \\ Magand, G. Louvel, J. Hadoux, A. Berdelou, et al.
}

\section{To cite this version:}

M. Barat, L. Tselikas, T. de Baère, G. Gravel, S. Yevich, et al.. Thermal-ablation of vertebral metastases prevents adverse events in patients with differentiated thyroid carcinoma. European Journal of Radiology, 2019, 119, pp.108650 -. 10.1016/j.ejrad.2019.108650 . hal-03487442

\section{HAL Id: hal-03487442 https://hal.science/hal-03487442}

Submitted on 20 Dec 2021

HAL is a multi-disciplinary open access archive for the deposit and dissemination of scientific research documents, whether they are published or not. The documents may come from teaching and research institutions in France or abroad, or from public or private research centers.
L'archive ouverte pluridisciplinaire HAL, est destinée au dépôt et à la diffusion de documents scientifiques de niveau recherche, publiés ou non, émanant des établissements d'enseignement et de recherche français ou étrangers, des laboratoires publics ou privés.

\section{(ㄷ)(1) $\$$}

Distributed under a Creative Commons Attribution - NonCommerciall 4.0 International 


\section{Thermal-ablation of vertebral metastases prevent adverse events in patients with differentiated thyroid carcinoma}

Details for each author are as follows:

M. Barat ${ }^{1}$, MD, maxime.barat89@gmail.com, corresponding author.

L. Tselikas ${ }^{1}$, MD, lambros.tselikas@gustaveroussy.fr

T. de Baère ${ }^{1}, \mathrm{MD}, \mathrm{PhD}$, Thierry.debaere@gustaveroussy.fr

G. Gravel ${ }^{1}$, MD, guillaume.gravel@gustaveroussy.fr

S. Yevich ${ }^{1}, \mathrm{MD}$, steven.yevich@duke.edu

A. Delpla ${ }^{1}, \mathrm{MD}$, adelpla@hotmail.fr

N. Magand ${ }^{1}$, MD, nicolas-magand@ hotmail.fr

G. Louvel ${ }^{2}$, MD, guillaume.louvel@gustaveroussy.fr

J. Hadoux ${ }^{3}$, MD, julien.hadoux@gustaveroussy.fr

A. Berdelou ${ }^{3}, \mathrm{MD}$, amandine.berdelou@gustaveroussy.fr

M. Terroir ${ }^{3}$, MD, marie.terroir-cassou-mounat@gustaveroussy.fr

E. Baudin ${ }^{3}, \mathrm{MD}, \mathrm{PhD}$, eric.baudin@gustaveroussy.fr

M. Schlumberger ${ }^{3}, \mathrm{MD}, \mathrm{PhD}$, martin.schlumberger@gustaveroussy.fr

S. Leboulleux ${ }^{3}, \mathrm{MD}, \mathrm{PhD}$, sophie.leboulleux@gustaveroussy.fr

F. Deschamps ${ }^{1}$ MD, PhD, frederic.deschamps@gustaveroussy.fr

1 - Department of interventional radiology, Gustave Roussy - Cancer Campus, 114 Rue Edouard Vaillant, 94800, Villejuif, France. +33 (0)1 42115428 Fax : +33 (0)1 42115052

2 - Department of radiotherapy, Gustave Roussy, 114 Rue Edouard Vaillant, 94800, Villejuif, France.

3 - Department of nuclear medicine and endocrine oncology, Gustave Roussy, Université Paris Saclay- 114 Rue Edouard Vaillant, 94800 Villejuif, France 


\section{Thermal-ablation of vertebral metastases prevents adverse events in patients with differentiated thyroid carcinoma}

KEY WORDS

Thyroid carcinoma - Neoplasm metastases - Ablation techniques/methods Spine

Word count: 2591 words

Number of Tables: 3

Number of figures: 4

Disclosure statement: The authors have nothing to disclose.

Financial support: none 


\section{Abstract (248 words):}

Purpose: To evaluate a strategy that used thermal-ablation of vertebral metastases (VM) to prevent vertebral related events (VRE) in patients with differentiated thyroid cancer (DTC).

Methods: This single center study retrospectively reviewed records and postoperative imaging of all DTC patients treated with thermal-ablation for asymptomatic VMs. Rate of local tumor control at first post-operative imaging, 12 and 24 months after thermal-ablation and rate of VREs at 12 and 24 months among the treated VMs were reported. New VMs that occurred during the follow-up and were not considered for additional thermal-ablation were moniroted and VREs were reported.

Results: Thermal-ablation was used to achieve local control of 41 VMs in 28 patients. Median post-treatment follow-up was 22 months [range: 12-80] and the mean delay for first post-operative imaging was 2 months [range: 0.6-7.5]. Local control at first post-operative imaging, 12 and 24 months was achieved in $87.8 \%$, $82.9 \%$ and $75.6 \%$, respectively. Among the treated VMs the rates of VRE was $7.3 \%$ at 2 years, significantly lower if local control was achieved at first post-operative imaging than if it was not ( $0 \%$ vs $30 \%, p=0.011, \mathrm{OR}=0.184[95 \% \mathrm{Cl}=0.094-0.360]$ ). After thermal-ablation procedures, 19 news VMs occurred in 11 patients (39.2\%) with a median interval of 8 months [range 1-26] and remained untreated. Among these untreated VMs, the rate of VREs at 2 years was significantly higher compared to the treated VMs: $(36.8 \%$ vs. $7.3 \%, \mathrm{p}=0.008, \mathrm{OR}=0.135,[95 \% \mathrm{Cl}=0.030-0.607])$.

Conclusion: local tumor control of VMs using thermal-ablation decreases the risk of VREs in DTC patients. 


\section{Abbreviations:}

${ }^{18}$ FDG: 18-fluorodesoxyglucose

CT: computed tomography

DTC: differentiated thyroid carcinoma

MRI: magnetic resonance imaging

PET: positron emission tomography

SBRT: Stereotaxic body radiotherapy

SINS: spinal instability neoplastic score

VM: vertebral metastasis

VRE: vertebral related event 


\section{INTRODUCTION}

Thyroid cancers are increasing in worldwide prevalence and represent approximately $2 \%$ of all malignancies [1]. The majority are differentiated thyroid cancers (DTC) (95\%) and associated with a long life expectancy and 10-year overall survival rate ranging between $80-95 \%$ [2]. Distant metastases occur in $10-15 \%$ and metastatic status decreases 10-year overall survival to approximately $50 \%[3,4]$. The most frequent distant metastatic sites are to the lung (50\%) and bone (25\%), of which $80 \%$ are located in the axial skeleton [3,4]. Focusing upon osseous metastases, $10 \%$ exist at the time of the diagnosis and $90 \%$ are subsequently discovered during follow up [3]. The lytic destruction from osseous metastases to the spine can result in debilitating vertebral related events (VREs) that include pathologic fractures, or spinal cord compression [5].

The majority of osseous metastases from DTC are diagnosed early during screening imaging exams, when the patient is asymptomatic [5]. Asymptomatic presentation often delay treatment, however a devastating VRE occurs in $78 \%$ of patients with untreated vertebral metastases (VM) mostly early after their first identification [6]. The potential pain and neurological compression from VREs can result in significant decreased quality of life and limited autonomy. Furthermore, the occurrence of a VRE can be a foreboding change of course for patients. Indeed, a first VRE has been shown to be an independent prognostic factor for subsequent VREs within the 10 next months [7]. Moreover, in this study the occurrence of VRE was independently associated with a poor overall-survival on multivariate analysis with a hazard ratio of $4.43(95 \% \mathrm{Cl}: 1.38-14.28)$ [7]. 
Considering the poignant sequelae of VREs, a proactive local tumor control of VM from DTC may be in the patient's best interest even if the VMs are asymptomatic in order to improve patient quality of life. The purpose of this study was to evaluate a preventive strategy that utilizes thermal-ablation to achieve local tumor control VMs in asymptomatic patients with DTC with the intended goal to decrease the occurrence of VRES. 


\section{MATERIALS AND METHODS}

This retrospective single center study had institutional board review approval and written consent was waived in accordance with our institution's policy on chart reviews. Records and post-operative imaging of all DTC patients treated with thermal-ablation for VMs between January 2008 and February 2017 were retrospectively reviewed. Inclusion criteria were asymptomatic patients with less than five VMs located from C2 to S5 and with a minimal follow-up of 12 months. Vertebral metastases were diagnosed using a combination of morphological (MRI or CT) and functional ( ${ }^{18}$ FDG-PET or ${ }^{131}$-scintigraphy) imaging methods. Decision to treat was determined by multidisciplinary tumor board, with the objective to provide a local tumor control of all existing vertebral metastases at time of treatment (defined as the time of thermal-ablation procedure). Exclusion criteria were 1) Symptomatic VM; 2)

prior VRE at the treated $\mathrm{VM}$; 3) prior curative treatment of the treated $\mathrm{VM}$ by stereotactic radiotherapy or surgical resection; and 4) patients with less than 12 months imaging follow-up.

Patients' records were retrospectively reviewed for patients' demographics, primary tumor and VMs' characteristics including the spinal instability neoplastic score (SINS) were reported (table 2) [8-10].

All procedures were performed under CT guidance with general anesthesia by staff interventional radiologists with greater than 5 years experience in thermalablation techniques. For all procedures, CT-scan was used to guide the placement of the needles (General Electric Healthcare, Little Charlfont, Buckinghamshire, United Kingdom). Thermal-ablations were performed either by radiofrequency ablation using a straight needle (Cool-Tip $\AA$; Covidien, Boulder, Colorado) or by cryoablation using a 
straight needle (Galil medical, Yokneam, Israel). The selection of the ablation modality, needle type, and time to treat were based on tumor size, location, and adjacent neurological structures. According to the multidisciplinary tumor board recommendation, injection of polymethyl methacrylate within the VM (percutaneous vertebroplasty) was performed for some patients in order to achieve a preventive consolidation during the same procedure. The association of vertebroplasty with thermal-ablation was recorded and morphological results rated according to the Saliou scoring system [11]. Treatment related complications were classified from 0 to 5 using the Clavien-Dindo complication's score (Supplemental materials) [12].

All pre- and post-operative imaging modalities were reviewed to report the rate of local tumor control at first post-operative imaging, at 12 and at 24 months, and to report the occurrence of VREs after treatment. The imaging follow-up included a MRI exam at 3, 6, 12 months after the treatment and then every years. When patients had hypermetabolism on pre-therapeutic imaging, ${ }^{18} \mathrm{FDG}$ PET monitoring was associated. For VM without FDG uptake before thermal-ablation, local tumor control was defined as the absence of residual tumor enhancement on MRI. For VM with FDG uptake before the thermal-ablation, local tumor control was defined as the absence of residual tumor enhancement on MRI and/or no residual tumor uptake on ${ }^{18}$ FDG-PET during imaging follow-up. Contrariwise, the absence of local tumor control was considered when ablation scars had a remaining nodular or irregular FDG uptake on post ablation ${ }^{18} \mathrm{FDG}$ PET CT scan in case of hypermetabolism on pre-therapeutic imaging or when residual tumor was found with nodular, irregular gadolinium enhancement or tumoral progression on post ablation MRI [13]. VREs were defined as fracture of a vertebral body, spinal cord compression or cauda equina syndrome requiring surgery and/or radiotherapy [7]. The rate of VRE was compared at 12 
months and at 24 months between the VMs that demonstrated local tumor control and the VMs that demonstrated incomplete tumor control on the first post-operative imaging.

The occurrence of news VMs on post-operative imaging was reported. Time of initial diagnostic of new VMs was defined as the time of bone metastases progression. The mean delay between the time of treatment and the time of bone progression was reported. The characteristics of new VMs were also reported. These new VMs were not considered for thermal-ablation by multidisciplinary decision, because a local treatment strategy was challenged by the progressive disease status. These new VMs were described as "untreated VMs" in this study. We compared the characteristics of untreated VMs at time of bone progression, the characteristics of treated VMs at time of the treatment. We also compared the rate of VRE among the treated VMs at 12 and 24 months after the treatment to the rate of VRE among the untreated VMs at 12 and at 24 months after time of bone progression.

For the statistical analysis, quantitative values were expressed as mean \pm standard deviation (SD) and compared using the Student t-test or non parametric Mann-Whitney U-test when effective tested were $<30$. Qualitative values were expressed in percentage and compared using a Chi-2 test or Fisher's exact test when attended observations were under 5 . Odds ratios and confidence intervals were calculated to compare the VRE risk between the treated and the untreated VMs. VRE free survival curves were built using the Kaplan-Meier methods and compared using the log-Rang test. The statistical significance for all tests was set at $p<0.05$. The SPSS version 20.0 (SPSS, IBM, USA) was used for all the statistical analyses. 


\section{RESULTS}

Twenty-eight patients (11 men, 17 women, median age was 56 [range: 27-72] years old at initial cancer diagnosis and 60 [range: 28 - 82] years old at time of treatment) were included for analysis (Figure 1). Initial patient characteristics and tumor history including FDG uptake, and characteristics of refractoriness to radioactive iodine are summarized in table $1[8,9]$.

At time of treatment, patients had a median of 1 [range: 1-4] vertebral metastases. A total of $41 \mathrm{VMs}$ were treated with thermal-ablation. Characteristics of treated VMs at time of treatment are summarized in table 2. Twenty-nine VMs were located in the vertebral body, while 12 were located in the posterior vertebral arch. The median VM diameter was $15 \mathrm{~mm}$ [range: 5-48]. The median SINS score was 6 [range: 2-14] and the median distance to the medullary canal was 5.5 [range: 1-17]. The majority of VMs were Iytic $(n=28)$, including 3 with paravertebral soft tissue extension. Treated VMs disclosed FDG uptake in $33 \mathrm{VMs}$ and radioactive iodine uptake in 23 VMs.

All thermal-ablations were successfully performed. The median post-operative hospitalization was 2 [range: $2-5$ ].

Two patients had treatment related complications consisting in transient paraesthesia and mild lower extremity pain after cryoablation of lesions at T11 and L1. These complications were classified as Clavien-Dindo grade II and resolved spontaneously within 2 weeks.

The median post-treatment follow-up was 22 months [range: 10-80]. All the 28 patients and 41 treated metastases (100\%) were followed 1 year and more, 15/28 patients $(55 \%)$ and $25 / 41$ metastases $(61 \%)$ were followed 2 years or more. The 
median delay for the first post-operative imaging after the treatment was 2 months [range: 0.6-7.5]. Local tumor control at first post-operative imaging, 12 and 24 months was achieved in $87.8 \%, 82.9 \%$ and $75.6 \%$, respectively. Three VREs occurred among the 41 treated VMs (7.3\%) with a median delay of 8 months [range: 1.9-20.7] after the treatment. All these VREs were metastatic epidural progression requiring surgical decompression and associated radiotherapy in 2 patients and radiotherapy only in one patient. Rate of VREs was significantly lower for VMs that demonstrated a local tumor control at first post-operative imaging compared to VMs that demonstrated incomplete tumor control on the first post-operative imaging. VREs occurred in $0 \%$ if controlled vs $60 \%$ if uncontrolled $(<0.001 \mathrm{OR}=0.104[95 \% \mathrm{Cl}=$ $0.042-0.266])$ respectively at 12 months. No difference was found for any other tested factors (Table 2).

Nineteen new VMs occurred during the post treatment follow-up in 11 patients with a median of 1 [range: 1-4] VMs per patient. Time of bone progression occurred with a median delay of 8 months [range: 1-26] after treatment. After multidisciplinary staff, none of these new VMs were considered for local treatment. At time of bone progression, these untreated VMs were asymptomatics and their characteristics didn't differ from significantly from the treated VMs except for lower SINS value, $4.9 \pm$ 1.2 vs. $6.2 \pm 2.3, p=0.04$ (table 3 ).

For untreated VMs, the median follow-up was 2 years [range: 1.1-5.9]. Eight of the eleven patients with $17 / 19(89 \%)$ of untreated metastases were followed one year or more and $3 / 11$ patients $(27 \%)$ with $7 / 19$ metastases $(37 \%)$ were followed two years or more. Seven VREs occurred among the 19 untreated vertebras (36.8\%) with a median delay of 12 months [range: 2.1 - 20.3] after time of bone progression. All these VREs were metastatic epidural progression, including one associated with a 
pathological vertebral fracture and spinal cord compression. The management of these VREs were surgical decompressions $(n=5)$, radiotherapy $(n=1)$ and association of surgical decompression and radiotherapy $(n=1)$.

The rate of VREs at 24 months was significantly lower for treated VMs compared to untreated VM $(7.3 \%$ versus $36.8 \% \mathrm{p}=0.008$, odds ratio $=0.135[95 \% \mathrm{Cl}$ $=0.030-0.607])($ Table 3$)($ Figures $2-4)$. 


\section{DISCUSSION}

The presence of asymptomatic VMs from non-medullary thyroid cancer often presents a problematic treatment decision conundrum. VREs are associated with a decrease of quality of life and overall survival [5]. Local tumor control of these VMs may have substantial impact and prevent grave sequel requiring additional interventions; however, intervention is traditionally considered high-risk due to the proximity of vital neurovascular structures. Recent technological advancements in non-invasive therapies for bone metastases are associated with a low rate of complications and might provide valid treatment alternatives to provide safe proactive preventive treatment [5].

Several treatment options are available to provide local treatment for VMs. Surgical corpectomy is the most effective in terms of local disease control; however, this surgical intervention is often considered excessively invasive especially as a preventive strategy in an asymptomatic patient as the potential surgical complications can be severe with nerve injury, infection, and prolonged recovery period [14, 15]. Stereotaxic body radiotherapy (SBRT) has proven to serve an increasing role in the management of VMs by the application of image-guided high-dose radiation to increase tumoral toxicity and reduce radiation induce tissue injury [16]. SBRT local control for spine metastases was reported at $86 \%$ for one-year bone metastases without tissue extension and $46 \%$ for bone metastases with soft tissues extension [17], although risks include vertebral fractures in $10-40 \%$ due to radiation osteolysis within the treatment field $[18,19]$. Percutaneous thermal-ablation therapies provide an alternative minimally invasive treatment option and have proven efficacy in multiple tumor types and metastatic locations [20]. For bone metastasis, the rate of 
local tumor control for percutaneous thermal-ablation appears related to tumoral size with 1-year local control of $85 \%$ for metastases under $2 \mathrm{~cm}, 81 \%$ in lesions between 2-3 $\mathrm{cm}$, and $40 \%$ for lesions over $3 \mathrm{~cm}[21]$.

Recently, the American thyroid association includes percutaneous interventional radiology in the management of metastatic DTC in two situations including ours: 1) In association with systemic treatment when metastases are symptomatic or have a high risk of focal complication; 2) In case of remaining distant focal metastasis after systemic treatment [22]. Cazzato et al. recently published a review of interventional radiology treatments of metastases for DTC and found promising results for overall survival with $71.6 \%, 66.8 \%$ and $60.1 \%$ at 1,2 and 3 years, respectively for bone metastases treated with thermal ablation with or without combination of cementoplasty [23]. However, no study specifically evaluated quality of life improvement or VRE prevention as in our study.

Our results suggest that proactive local tumor control of asymptomatic VMs significantly decreases the occurrence of VREs with a hazard ratio of $0.135[95 \% \mathrm{Cl}=$ $0.030-0.607]$. Given these findings we suggest that preventive thermal-ablation of VMs from DTC should be discussed at tumor board, especially in long life expectancy patients, even if asymptomatic.

Our results highlighted the importance of a local tumor control of the VMs. Indeed, the risk of VREs was significantly higher after incomplete tumor control compared to local tumor control. Based on this result, we believe that post-operative imaging is key to depict a residual disease after thermal-ablation and to discuss an additional local treatment to definitively achieve local tumor control the VMs, such as another session of thermal-ablation or SBRT. For this purpose, we recommend an early first post-operative imaging using. The optimal delay has not been investigated 
yet. It must take into account, the inflammatory process around the thermal-ablated area that could hide residual disease. A first post-operative imaging at 6 weeks could be a good compromise.

The main limitations of our monocentric study include a relatively small cohort and its retrospective design. However, this is the first cohort to evaluate proactive preventive treatment in patients with asymptomatic VMs. The retrospective design induces some bias and do not allow to conclude with strong evidence. However, the benefit of a preventive strategy is difficult to evaluate in this rare pathology, requiring very large patients cohort, randomization and prolong follow-up. To overcome this biais we decided to use patients as their own control, comparing VMs treated with thermal-ablation and VMs not treated with thermal-ablation. To limit the bias between the 2 groups we compared the characteristics of the treated VMs at time of their treatment and the characteristics of the untreated VMs at time of bone metastases progression. We didn't find any difference between the two groups except a higher SINS score in the treated group, demonstrated a higher risk of fracture in the treated group.

In conclusion, a proactive thermal-ablation of VMs in DTC patients appears to decrease the occurrence VRE. This treatment strategy provides high rate of local tumor control, low complication rate and short post procedure hospitalization After thermal ablation, an early post-operative imaging must be performed to detect residual disease and to discuss additional local treatments, such as additional thermal-ablation or SBRT.

\section{Author disclosure statement:}

The authors declares that they have no competing interests regarding to this study 


\section{References}

1. society, A.c., Key statistics of thyroid cancer. https://www.cancer.org/cancer/thyroid-cancer/about/key-statistics.html, 2018.

2. Schlumberger, M.J., Papillary and follicular thyroid carcinoma. N Engl J Med, 1998. 338(5): p. 297-306.

3. Muresan, M.M., et al., Bone metastases from differentiated thyroid carcinoma. Endocr Relat Cancer, 2008. 15(1): p. 37-49.

4. $\quad$ Carling, T. and R. Udelsman, Thyroid cancer. Annu Rev Med, 2014. 65: p. 125-37.

5. Choksi, P., et al., Skeletal Complications and Mortality in Thyroid Cancer: A Population-Based Study. J Clin Endocrinol Metab, 2017. 102(4): p. 1254-1260.

6. Robenshtok, E., et al., Natural history of small radioiodine-avid bone metastases that have no structural correlate on imaging studies. Endocrine, 2014. 47(1): p. 266-72.

7. Farooki, A., et al., Skeletal-related events due to bone metastases from differentiated thyroid cancer. J Clin Endocrinol Metab, 2012. 97(7): p. 2433-9.

8. Schlumberger, M., et al., Definition and management of radioactive iodinerefractory differentiated thyroid cancer. Lancet Diabetes Endocrinol, 2014. 2(5): p. 356-8.

9. Robbins, R.J., et al., Real-time prognosis for metastatic thyroid carcinoma based on 2-[18F]fluoro-2-deoxy-D-glucose-positron emission tomography scanning. J Clin Endocrinol Metab, 2006. 91(2): p. 498-505.

10. Fourney, D.R., et al., Spinal instability neoplastic score: an analysis of reliability and validity from the spine oncology study group. J Clin Oncol, 2011. 29(22): p. 3072-7.

11. Saliou, G., et al., Percutaneous vertebroplasty for pain management in malignant fractures of the spine with epidural involvement. Radiology, 2010. 254(3): p. 88290.

12. Dindo, D., N. Demartines, and P.A. Clavien, Classification of surgical complications: a new proposal with evaluation in a cohort of 6336 patients and results of a survey. Ann Surg, 2004. 240(2): p. 205-13.

13. Gravel, G., et al., Early detection with MRI of incomplete treatment of spine metastases after percutaneous cryoablation. Eur Radiol, 2019.

14. Deschamps, F., et al., Thermal ablation techniques: a curative treatment of bone metastases in selected patients? Eur Radiol, 2014. 24(8): p. 1971-80.

15. Laredo, J.D., et al., Vertebroplasty and interventional radiology procedures for bone metastases. Joint Bone Spine, 2018. 85(2): p. 191-199.

16. Wu, X., et al., Palliative Surgery in Treating Painful Metastases of the Upper Cervical Spine: Case Report and Review of the Literature. Medicine (Baltimore), 2016. 95(18): p. e3558.

17. Sahgal, A., et al., Stereotactic body radiotherapy for spinal metastases: current status, with a focus on its application in the postoperative patient. J Neurosurg Spine, 2011. 14(2): p. 151-66.

18. Foro Arnalot, P., et al., Randomized clinical trial with two palliative radiotherapy regimens in painful bone metastases: 30 Gy in 10 fractions compared with 8 Gy in single fraction. Radiother Oncol, 2008. 89(2): p. 150-5.

19. Mizumoto, M., et al., Radiotherapy for patients with metastases to the spinal column: a review of 603 patients at Shizuoka Cancer Center Hospital. Int J Radiat Oncol Biol Phys, 2011. 79(1): p. 208-13. 
20. Sahgal, A., et al., Vertebral compression fracture after stereotactic body radiotherapy for spinal metastases. Lancet Oncol, 2013. 14(8): p. e310-20.

21. Deschamps, F., G. Farouil, and T. de Baere, Percutaneous ablation of bone tumors. Diagn Interv Imaging, 2014. 95(7-8): p. 659-63.

22. Haugen, B.R., et al., 2015 American Thyroid Association Management Guidelines for Adult Patients with Thyroid Nodules and Differentiated Thyroid Cancer: The American Thyroid Association Guidelines Task Force on Thyroid Nodules and Differentiated Thyroid Cancer. Thyroid, 2016. 26(1): p. 1-133.

23. Cazzato, R.L., et al., Current role of interventional radiology in the management of visceral and bone metastases from thyroid cancer. Gland Surg, 2018. 7(2): p. 8088. 
Figures legends:

Figure 1: Flowchart of patients included for analysis.

Figure 2.

62 years old woman with a 9 years history of thyroid papillary carcinoma previously treated with total thyroidectomy and radioactive iodine therapy with initial ${ }^{18} \mathrm{FDG}$ uptake. Preoperative axial T1-weighted enhanced MRI demonstrates a $27 \mathrm{~mm}$ metastasis of the L3 body (a) with soft tissues extension (arrows). Perprocedure CT image with maximal intensity projection demonstrates three cryoablation probes used for thermal-ablation of the metastasis (b). Three months post-procedure axial T1weighted enhanced MRI shows complete local treatment with an expected thin peripheral enhancing scar tissue (arrows) (c). A 24 months post-procedure axial ${ }^{18}$ FDG-PET CT-scan without metabolic activity and no vertebral related event (d). 


\section{Figure 3.}

62 years old woman with a history of thyroid papillary carcinoma, treated with total thyroidectomy, radioactive iodine therapy, and two lines of systemic treatment (sorafenib and pazopanib). Pre-procedure axial non-enhanced CT-scan shows a $19 \mathrm{~mm}$ metastasis in the right part of the C6 vertebral body (a) with soft tissues extension (arrows). Per-procedure CT image shows the cryoablation probe used for ablation (b). One month post-procedure axial enhanced T1-weighted MRI (c) and ${ }^{18}$ FDG-PET CT-scan (d) shows residual enhancement of the tumor soft tissue component (arrows) and hypermetabolism of the residual tumor tissue with SUV = 8.6. Three months post-procedure axial T1-weighted enhanced MRI (d) shows tumor growth with epiduritis along the posterior vertebral body wall and spinal cord compression (arrows). This residual tumor resulted in epiduritis with paresthesia requiring radiotherapy in emergency. 


\section{Figure 4.}

54 years old woman with a history of thyroid papillary carcinoma diagnosed 9 years ago previously treated with total thyroidectomy, radioactive iodine therapy, and two lines of systemic treatment (sorafenib and sunitinib). During screening follow-up, a T6 vertebral metastasis was identified 4 years after initial diagnosis. This lesion was completely treated with thermal-ablation without any VREs during the 5year subsequent follow-up. Bone progression occurred 7 years after initial diagnosis. The MRI demonstrated a vertebral metastasis located in the anterior part of the T10 vertebral body: sagittal T1-weighted enhanced MRI (a) and sagittal T2-STIR weighted MRI (b). No local treatment of this new vertebral metastases was pursued. Twenty months after diagnosis of this vertebral metastasis, a sagittal T1-weighted enhanced MRI (c) shows an enlarging tumor with pathological vertebral fracture of the anterior vertebral body and a posterior epiduritis with spine cord compression (arrow). Sagittal enhanced CT-scan (d) shows extension throughout the T10 body with posterior involvement and spinal cord compression (arrow). The patient died one month after from physical decline. 
79 patients identified

24 patients with medullary thyroid cancer

9 patients with a follow up less

than 12 months:

- 4 deaths

- 5 lost of follow-up

\section{8 patients included:}

- 41 treated vertebral metastases

- 19 new and untreated vertebral metastases 


\section{a}
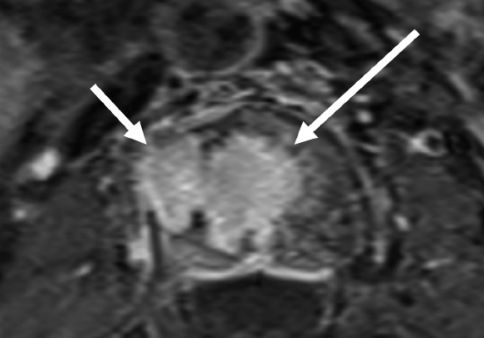

.

C

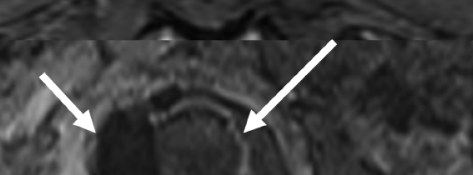

d 2 h

2) Yyis 2. S w

E Q) (a) surest

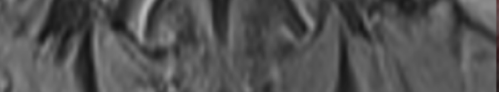

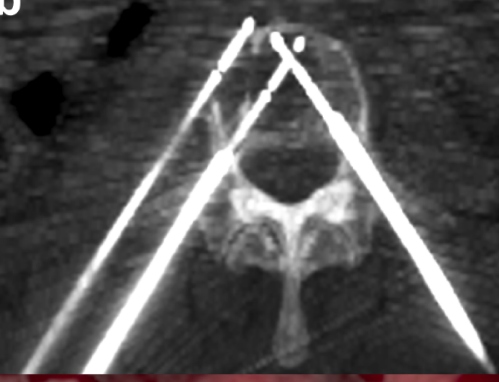

a.

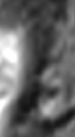

(x)

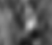

\&. 


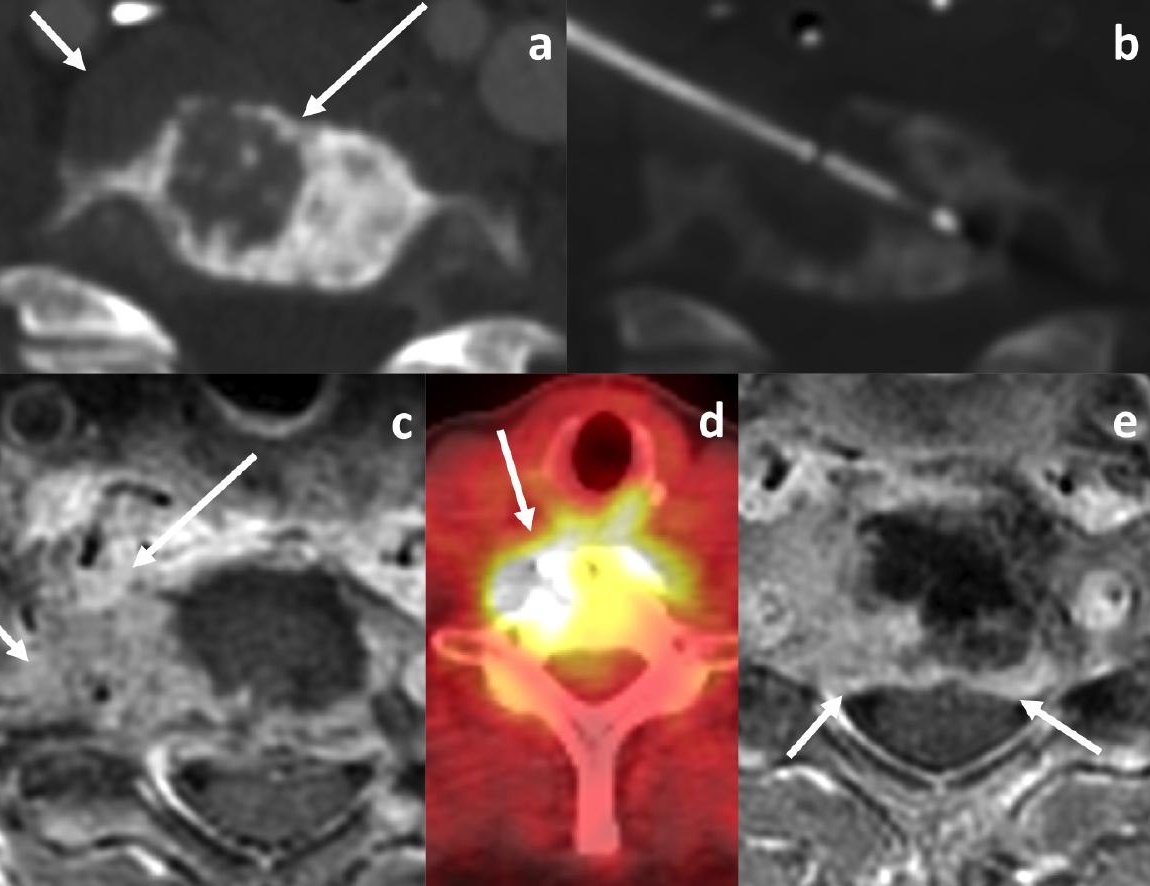


a

$$
4
$$

m

b

C
(9)

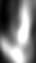

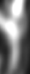

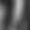

(1)

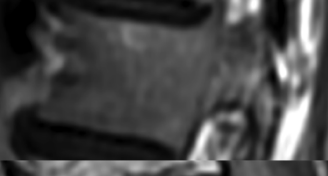

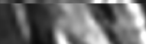
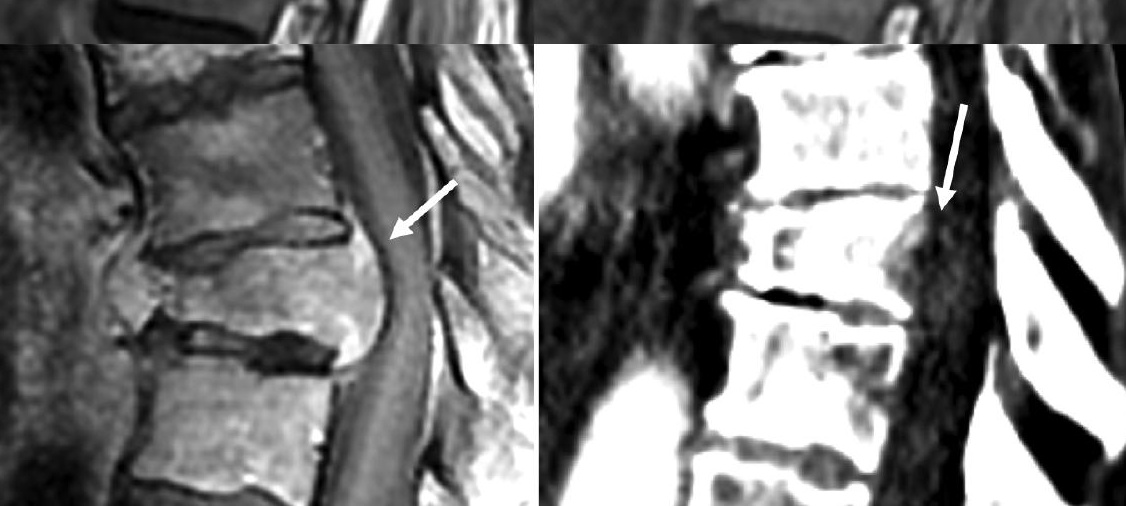


\begin{tabular}{|c|c|}
\hline $\mathbf{N}=\mathbf{2 8}$ & Patients \\
\hline Sex male/female & $11(30.3 \%) / 17$ (60.7\%) \\
\hline Age at diagnosis & $52 \pm 12$ [Range: $27-72$ ] \\
\hline Age at thermal-ablation & $58 \pm 13$ [Range: $28-82$ ] \\
\hline Follow up after treatment (years) & $2.7 \pm 1.5$ [Range: $1-6.7]$ \\
\hline \multicolumn{2}{|l|}{ Histology } \\
\hline Papillary carcinoma & $8(28.6 \%)$ \\
\hline Follicular carcinoma & $16(57.1 \%)$ \\
\hline Poorly differentiated carcinoma & $3(10.7 \%)$ \\
\hline Hurtle cell cancer & $1(3.6 \%)$ \\
\hline \multicolumn{2}{|l|}{ Stage at diagnosis } \\
\hline \multicolumn{2}{|l|}{$\mathrm{T}$} \\
\hline 1 or 2 & 5 (17.9\%) \\
\hline 3 or 4 & $23(82.1 \%)$ \\
\hline $\mathrm{N}+$ & $28(100 \%)$ \\
\hline \multicolumn{2}{|l|}{ M } \\
\hline Bone & $17(60.7 \%)$ \\
\hline Liver & $3(10.7 \%)$ \\
\hline Lung & $7(25.0 \%)$ \\
\hline Nodes & $8(28.6 \%)$ \\
\hline \multicolumn{2}{|l|}{ Previous systemic treatments } \\
\hline $\mathrm{I}^{131}$ therapy & $28(100 \%)$ \\
\hline Resistant to radioactive iodine & $20(71.4 \%)$ \\
\hline \multicolumn{2}{|l|}{ Line of other systemic treatment } \\
\hline 1 & $13(46.8 \%)$ \\
\hline 2 & $8(28.7 \%)$ \\
\hline 3 & $3(10.8 \%)$ \\
\hline$\geq 4$ & $1(3.6 \%)$ \\
\hline Tyrosine Kinase inhibitors & $14(50 \%)$ \\
\hline Systemic chemotherapy & $3(10.8 \%)$ \\
\hline Immunotherapy & $1(3.6 \%)$ \\
\hline Denosumab & $10(35.7 \%)$ \\
\hline
\end{tabular}

Table 1. Patients' and primary tumors' characteristics at time of treatment. Quantitatives values are expressed as mean $\pm S D$. Qualitatives values are expressed as number and percentages. 


\begin{tabular}{|c|c|c|c|}
\hline & VRE $n=3$ & No VRE $n=38$ & P-Value \\
\hline \multicolumn{4}{|l|}{ Patients $(n=28)$} \\
\hline $\operatorname{Sex}(M / F)$ & $2 / 1$ & $10 / 14$ & $0.667^{*}$ \\
\hline Age (years) & $60.7 \pm 2.3$ & $58.2 \pm 13.9$ & $0.767^{\#}$ \\
\hline RAI refractory yes/no & $3 / 0$ & $28 / 8$ & $0.593 *$ \\
\hline \multicolumn{4}{|l|}{ Treated vertebral metastases $(n=41)$} \\
\hline Located in the vertebral body & 1 & 28 & \multirow{2}{*}{0.158} \\
\hline Located in the vertebral arch & 2 & 10 & \\
\hline Lysis/osteosclerosis & $3 / 0$ & $35 / 3$ & 0.880 \\
\hline Lesion diameter $(\mathrm{mm})$ & $15.1 \pm 7.1$ & $16.7 \pm 9.3$ & $0.527^{\#}$ \\
\hline Distance to canal (mm) & $4.7 \pm 1.5[3-6]$ & $6.1 \pm 4.1[1-17]$ & $0.550^{\#}$ \\
\hline SINS score & $8.3 \pm 2.5$ & $5.9 \pm 2.4$ & $0.095^{\#}$ \\
\hline Epiduritis (Yes/No) & 0 & 0 & $1.000 *$ \\
\hline Vertebra fracture (Yes/no) & $0 / 3$ & $0 / 38$ & $1.000^{*}$ \\
\hline Soft tissues extension (Yes/No) & $1 / 2$ & $2 / 36$ & $0.072^{*}$ \\
\hline Radiotherapy before the treatment (Yes/No) & $0 / 3$ & $2 / 36$ & $0.684^{*}$ \\
\hline FDG uptake (Yes/No) & $3 / 0$ & $31 / 7$ & $0.561 *$ \\
\hline lodine uptake (Yes/No) & $0 / 3$ & $23 / 15$ & $0.244^{*}$ \\
\hline Previous Systemic treatment (Yes/No) & $1 / 2$ & $17 / 21$ & $0.702^{*}$ \\
\hline Denosumab during history (Yes/No) & $1 / 2$ & $15 / 20$ & $0.833^{*}$ \\
\hline \multicolumn{4}{|l|}{ Treatments $(n=41)$} \\
\hline Cryotherapy/Radiofrequency & $3 / 0$ & $31 / 7$ & $0.414^{*}$ \\
\hline Number of needles if cryotherapy & $1 \pm 0[1-1]$ & $1.7 \pm 0.6[1-3]$ & $0.667^{*}$ \\
\hline Vertebroplasty in association ( $n=12)$ (Yes/No) & $1 / 11$ & $2 / 27$ & 0.850 \\
\hline $\begin{array}{l}\text { Complete local treatment at } 12 \text { months } \\
\text { (Yes/No) }\end{array}$ & $0 / 3$ & $36 / 2$ & $<0.001$ \\
\hline $\begin{array}{l}\text { Complete local treatment at } 24 \text { months } \\
\text { (Yes/No) }\end{array}$ & $0 / 3$ & $22 / 7$ & 0.011 \\
\hline
\end{tabular}

Table 2. Occurrence of vertebral related event (VRE) according to the characteristics of the patients, the characteristics of the treated vertebral metastases and the characteristics of the treatments. Quantitatives values are expressed as mean \pm SD. Numbers in brackets are range.

* Chi-2 or Fischer test. \#Student t-test. Number in bold are P-values $<0.05$. 


\begin{tabular}{|c|c|c|c|}
\hline & $\begin{array}{c}\text { Treated VMs at time of } \\
\text { the treatment }\end{array}$ & $\begin{array}{c}\text { Untreated VMs at time of } \\
\text { bone progression }\end{array}$ & $\begin{array}{l}\text { P- } \\
\text { Value }\end{array}$ \\
\hline$n=$ & 41 & 19 & \\
\hline \multicolumn{4}{|l|}{ Location } \\
\hline Cervical & $5(12.2 \%)$ & $3(15.8 \%)$ & $0.123^{*}$ \\
\hline Thoracic & $17(41.5 \%)$ & $13(68.4 \%)$ & \\
\hline Lumbar & $16(39.0 \%)$ & $3(15.8 \%)$ & \\
\hline Sacral (S1) & $3(7.3 \%)$ & $0(0.0 \%)$ & \\
\hline Tumor location (body/arch) & $29 / 12$ & $14 / 5$ & $0.824 *$ \\
\hline Larger diameter (mm) & $17.0 \pm 9.3[5-48]$ & $14.3 \pm 4.9[7-28]$ & $0.241^{\#}$ \\
\hline SINS [0-18] & $6.2 \pm 2.3[2-14]$ & $4.9 \pm 1.2[3-7]$ & $0.040 *$ \\
\hline Lytic/blast & $28 / 13$ & $15 / 4$ & 0.39 \\
\hline Follow-up (years) & $2.7 \pm 1.6[1.0-6.6] \ddagger$ & $2.4 \pm 1.2[1.1-5.9] \ddagger \ddagger$ & $0.509^{\#}$ \\
\hline VRE & $3(7.3 \%)$ & $7(36.8 \%)$ & $0.008 *$ \\
\hline Delay (months) & $8.2 \pm 5.4[1.9-20.7] \ddagger$ & $12.3 \pm 5.5[2.1-20.3] \neq \ddagger$ & $0.320^{\#}$ \\
\hline
\end{tabular}

Table 3. Characteristics of treated and untreated vertebral metastases (VMs) and occurrence of vertebral related event (VRE) in the 2 groups. Quantitatives values are expressed as mean \pm SD.

*Chi-2 or Fischer test. \# Student t-test. Numbers in bold are P-values under 0.05 .

¥ Follow-up from the time of the treatment. $\ddagger$ Follow-up from the time of bone progression. 